\title{
The Mersey Estuary Pollution Alleviation Scheme: Liverpool interceptor sewers
}

\section{G. N. Olsen, M. F. Danbury and B. Leatherbarrow}

Roger Pacey, Severn Trent Water Ltd

The scheme makes extensive use of novel developments of the previously conventional stilling pond overflow chambers after Sharpe and Kirkbride. The authors claim good solids retention with the sewerage system - even to the extent of having to recommission the northern outfall CSO because the Sandon inlet works could not deal with the resulting slug of solids (paragraph 71).

The authors are right to point out that the deep shaft form of CSO has potential in use with storage and pumped returns (paragraph 78). As such, have the authors any observations, measured or anecdotal, on the solids retention performance of the CSO? What is the amenity value placed on the receiving water for judging performance on aesthetic grounds, and how are the CSOs performing against the conventional (Urban Pollution Manual $^{14}$ ) criteria for these values?

\section{Author's reply}

The efficiency of the northern outfall CSO at the time of commissioning must be viewed conservatively in view of the fact that its highly effective performance was demonstrated by the chamber being full for a long period during dry weather. In this situation, the CSO chamber had much lower pass-through velocities than would usually be the case.

The deep shaft CSO is located at Dingle outfall L10. The original studies of performance included in the paper were limited to those outfalls north of and including outfall L9. Discussion with former colleagues at Liverpool who have continued with maintenance roles has indicated that no further recent analysis of the system performance data has been undertaken on behalf of North West Water.

The original modelling work was undertaken to develop the design criteria for both the rectangular and deep shaft overflows at Liverpool University, and it was always the intention that the actual structures be revisited in an attempt to compare actual performance with the model predictions. This has not taken place, possibly due to organizational changes and changes in priorities. There is clearly a need to undertake further investigations so as to establish actual performance data to enable a judgement to be made on the relative merits of the deep shaft and the possibility of using this design approach for tanks with pumped returns. Such investigations could also compare actual performance with current UPM criteria. Professor Richard Burrows (see further contribution) at Liverpool University who supervised the original modelling work, has retained some of the models, and would no doubt be willing to consider further model or prototype studies if approached.

As far as amenity value is concerned, it is understood that there is no formal established or general classification relating to the Mersey Estuary. Certainly, at the commencement of planning for the project, when performance criteria were expressed simply in terms of no fouling of beaches and maintenance of oxygen levels to obviate odour (paragraph 2), there were no classifications.

The construction programme and first years of operation have been paralleled by a great change in the perception and actual use of the Liverpool waterfront. In the 1970s, beaches at Crosby were regarded by many as not fit for water contact, that is, swimming, and would probably have been classified as moderate amenity. In south Liverpool, public promenades adjoining the river (with no water access) would have resulted in low amenity classification. Elsewhere, with the public denied access by docks, most stretches of the east bank would have been regarded as non-amenity.

The current position is very different. Crosby beaches would now be classified as high amenity. Virtually the whole waterfront south of Prince's Dock is now effectively open to the public, and the whole area has been given over to high-quality riverside houses, apartments, hotel, marina and museum/art gallery activities. Anglers now make catches of large fish along all of this waterfront, sea trout have been filmed attempting to leap Howley Weir at Warrington, and within the recent past a dolphin has been seen over several days opposite Albert Dock. It may be argued that the project has contributed to a total reclassification of the Liverpool waterfront, in amenity terms, to that of high amenity.

\section{R. Burrows and K. H. M. Ali, University of Liverpool}

The authors are to be congratulated on their preparation of such an informative account of the impressive sewerage scheme now in place in Liverpool. As one-time researchers on different aspects of the project, we now find it most beneficial to have an authoritative account of the whole scheme. Our contribution 
here focuses on the CSO design but also touches briefly on operational aspects.

The modelling work conducted in the hydraulics laboratories in the Civil Engineering Department at the University of Liverpool is outlined in the paper (paragraphs 17-19). We wish only to make several further comments and point out other publications arising from the work, which may be of interest to readers.

With the substantial depths available between the existing (shallow) outfall sewers and the deep interceptor, the novel 'circular shaft' overflow design, depicted in Fig. 5, $\operatorname{arose}^{10}$ as a result of the aims of

(a) maximizing storage volume, to so minimize the number of overspill events

(b) reducing the footprint of the structure and maximizing utilization of volumes excavated

(c) ensuring effective 'stilling' of the flows to provide efficient retention of gross solids.

The original study was for the city culvert structure and was completed in $1980 .{ }^{10}$ In the subsequent commission for outfalls L1-L5, over the period 1981-1984, constructional constraints led to the preference of rectangular box construction. A generic 'rectangular shaft' design evolved, suitable for differing chamber invert depths, where at the shallowest it took a form not greatly dissimilar from a standard 'Sharpe-Kirkbride' stilling pond. ${ }^{9}$

This modelling study is comprehensively reported in an earlier issue of the ICE proceedings. ${ }^{15}$ As well as fundamental contributions ${ }^{16}$ in the area of the scale modelling of the suspended particulate (generally represented by weighted wax spheres in the laboratory), innovative means of performance evaluation were advanced at the time ${ }^{17}$ so as to properly measure their beneficial performance against alternative structure types.

Both chamber designs (circular and rectangular shafts) remain novel and it should be of some interest to now consider fieldtesting of these unique chambers to ascertain their actual performance in solids retention, and to compare this against the observed behaviour in the laboratory. It would be interesting to know if such a study has been contemplated.

The work at the University of Liverpool also included simulations of the impacts of overflow chamber storage volume on the likely spill characteristics (volume, duration and number of events). ${ }^{15,18}$ Following from this, a brief exploratory evaluation of the scope and potential benefits of real-time control (RTC) of the extensive system was undertaken, it initially focusing on the maximum utilization of all chamber storage before first spill is permitted.

Ongoing academic research at the University of Liverpool, being conducted with cooperation from North West Water, is investigating the use of rigorous formal optimization procedures towards the incorporation of effective 'global' RTC on large interceptor systems. This is presently directed at the minimization of total pollution loads to the river over each rainfall event. The researcher on this topic, Neil Thomas, will offer his individual contribution to the discussion separately.

It would, nevertheless, be interesting to receive the views of the authors on the merits or otherwise of introducing a more integrated dynamic operational regime to the system and, indeed, any practical difficulties envisaged.

\section{N. S. Thomas, University of Liverpool}

I read your paper with interest, having researched the operation aspects of the Liverpool interceptor sewer system over the last few years at the University of Liverpool. I was particularly interested in the description of the performance of the scheme and would like to make a contribution about the potential improvements with the use of predictive RTC upon which my research has been focused.

The Civil Engineering Department at the University of Liverpool has had a long history of collaboration with the MEPAS, which was outlined in the paper (paragraphs 17-19). On the operational perspective, Professor Andrew Templeman has offered advice to the Liverpool City Engineer on the prospects for active control (1979) and a preliminary study of potential control models (1984). I have continued with this line of research, in collaboration with North West Water, as part of a $\mathrm{PhD}$ research programme on the optimal pollution control of interceptor sewer systems. It was interesting to read that the central Liverpool section of the scheme has made such significant improvements on the Mersey Estuary and noted that the authors considered there was scope for further improvement through moving to a predictive RTC approach (paragraph 77). Having researched this approach over the last three years using the Liverpool interceptor sewer as a test-bed, it may be beneficial to illustrate the potential magnitude of these further improvements.

The key issue with the RTC of sewerage systems is the computational efficiency of determining the control decisions. This problem gets exacerbated with large systems that include many control points, such as the scheme installed in Liverpool. As an illustration, if each of the penstocks, which control the inflows into the sewer, along the Liverpool interceptor had only two operational possibilities (fully open or closed), then there would be over 30 million possible control strategies at every time-step in the solution. Therefore, a control model is required to determine these control strategies very quickly. Much of the published work on RTC is based upon the use of detailed deterministic sewer simulation models. However, considerable computer time is required to investigate the consequences of a single set of control decisions. The determination of an optimal set of control decisions multiplies this computer time requirement several times.

In the work undertaken as part of the research programme, an optimal pollution control (OPC) model has been developed which uses a unique 'slug' flow approach for the modelling of the sewer flow hydraulics. ${ }^{19,20}$ The approach is based on the assumption that sewage diverted to the interceptor is represented as a 'slug' of sewage advecting at pipe-full velocity down the sewer. Slugs do not interact with the immediate upstream or downstream slugs and are incremented by sewage diverted to the interceptor at successive intercept points. A 
pollutant concentration factor is used to characterize the tributary sewer pollutant flows in each time interval. The control decisions are determined using either linear or dynamic programming to minimize the total pollutant load discharged to the receiving waters over the entire storm event. The models are computationally efficient since the models are not constrained to solve the full sewer hydraulics.

Applications of the control model to the northern leg of the Liverpool interceptor system have shown it offers significant environmental improvements over all other types of control systems. ${ }^{21}$ As an indication, results from a highly synchronized storm (where the improvements are likely to be the lowest, most improvements being encountered in storms with spatial and temporal distributions) show reductions in pollutant load spilled of $40 \%$ for low-intensity rainfall (i.e. peak inflow to the system at approximately 2 times 'formula A' settings) when using the OPC model compared to the existing fixed local control. The reductions reduced to $8 \%$ for a high-intensity rainfall (i.e. peak inflow to the system at approximately 10 times 'formula A' settings).

Verification studies ${ }^{22}$ on the model have shown that the control decisions generate flow regimes in the interceptor that are remarkably similar to those generated by WALLRUS. A postprocessing hydraulic verification routine was also developed where a quasi-steady approach was used to determine approximate interceptor sewer water profiles. The water profiles, validated to WALLRUS, show that the control decisions generate physically feasible solutions. Other results have shown that the 'slug' flow approach is not fully able to represent the interceptor sewer flow dynamics in storms that are localized in the downstream sections of the interceptor sewer. In such events, the storm flows utilize the available storage upstream and in these situations the model needs modifications to represent the sewage advection upstream. Nevertheless, the overall results have demonstrated the validity of the 'slug' flow approach and offer promise for practical implementation of optimal real-time control.

\section{Author's response}

The work undertaken by Liverpool University was given only a brief explanation in the paper due to limitation of space and a need to focus on a number of construction features. Professor Burrows and Dr Ali's discussion contribution provides a fuller explanation of the important modelling work undertaken, and the provision of the additional references will enable other engineers to apply and adapt the research to other circumstances.

The question of now considering the field-testing of the rectangular and circular chambers arises in the discussion contribution. Repeating the response to Roger Pacey, it can only be stated that it was always in our mind that the real structures should be studied for performance, but that organizational changes may have resulted in changed responsibilities and associated priorities.

Liverpool City Engineer's Department originally promoted the RTC aspects of this project. An initial approach was made to Liverpool University to develop a flow management system that could fully utilize all the storage in the system with predictive use of rain-gauge information from the catchment. This work did not proceed as there were doubts about the reliability of the then available equipment and there were risks associated with software development. However, the system was built so that it could be modified to perform in a predictive rather than reactive mode should further research take place and raingauges or other facilities be added later.

An alternative approach investigated after the latter decision was to avoid problematical rainfall measurement and to provide software that could compare pass-forward flows with the local and overall tunnel capacities available. Each catchment was to be weighted to take account of its particular trade effluents and outfall location, and flows could be discharged locally at a rate exceeding formula A depending upon available tunnel capacity and downstream catchment requirements. This alternative approach would have resulted in higher/more selective volumes being intercepted and treated. It was not adopted, presumably because the agreed discharge consents could be met without the refinement (which would have resulted in higher volumes to be treated).

There will undoubtedly be great benefits from applying a more integrated dynamic operational regime. While it may be argued that the benefits are limited in the context of the further gains to be made by further limiting the discharges, the additional cost of applying further controls continues to diminish in real terms.

Another benefit of improving the operational regime would arise if the CSO and interceptor sewer control and management were more fully integrated with the control and management of Sandon Dock itself. It would be logical for the operation and performance of Sandon Dock and the interceptor sewer system to be viewed as a single entity, and to be fully automated. The authors would endorse any proposal by Liverpool University, North West Water and the Environment Agency (EA) to complete and develop any current related research. The aim should be to optimize the management, control and operation of the overall system in the context of an improved application of the original control philosophy (paragraph 24, and paragraphs 35-45).

The contribution by Neil Thomas confirms the considerable additional control potential, and associated improvements, that could come from the further development and application of real-time control.

In the course of discussing current operational aspects of the scheme so as to provide up-to-date information in the discussion response, the authors were surprised to find that there are occasions when flows are stored in the interceptor sewer (i.e. the pump rate at Sandon does not always match the incoming flow (paragraph 24)), sometimes to the extent that some vortex connections drown out from downstream surcharge. This causes the CSO control penstocks to close completely, cutting off contributing flows until the tunnel levels subside and the system is reset. The reason for this departure from the original control philosophy, that is, accidental, technical or operational, was not immediately apparent. 
The authors assume that despite possible operational changes and the lack of further performance monitoring, the system overall more than meets the terms of current Environment Agency consents.

The need for further change or improvement is presumably linked to meeting EA standards or future requirements. The need for further research into CSO design or RTC will presumably depend upon whether there is a perceived benefit that could be applied to other systems or designs such as CSOs with pumped after-storm returns, and RTC that could be applied to other systems so as to produce economies in construction or the optimization of existing overloaded systems. The current trend toward specifying aesthetic outflow performance in terms of permissible particle sizes inevitably results in a preference for mechanical screening with minimum chamber dimensions. The performance of a deep shaft type of CSO will probably exceed the performance and reliability of a screened chamber in many respects, and be of lower operational and running cost even with pumped emptying. Without further research and prototype monitoring, it will be difficult to prove that this is, in fact, the case.

\section{REFERENCES}

14. Foundation for Water Research. Urban Pollution Managment Manual. A planning guide for the management of urban wastewater discharges during wet weather. The Foundation for Water Research, 1994.

15. Burrows R. and Ali K. H. M. A rectangular shaft configuration for storm sewage overflow structures, Part 2.
Proceedings of the Institution of Civil Engineers Research and Theory, 1988, 85, Sept., 435-455.

16. Ali K. H. M., Burrows R. and Lim S. V. Scale model investigation of stormwater overflows. In Hydraulic Modelling of Civil Engineering Structures. BHRA Publications, Cranfield, 1982, pp. 357-379.

17. Burrows R. and Ali K. H. M. Stormwater overflows: interpretation of particle retention test results. In Urban Drainage Systems (Featherstone R. E. and James A. (eds)). Pitman, London, 1982, pp. 57-72.

18. BURRows R. Storm water overflows: operational characteristics. Proceedings of the Institution of Civil Engineers Municipal Engineer, 1987, 4, Oct., 281-287.

19. Thomas N. S., Templeman A. B. and Burrows R. Optimal control models for interceptor sewer systems. Proceedings of Urban Drainage Modelling '98, Imperial College, London, September 1998, 691-698.

20. Thomas N. S., Templeman A. B. and Burrows R. Pollutant load overspill minimization of interceptor sewer systems. Engineering Optimization, 2000.

21. Thomas N. S., Templeman A. B. and Burrows R. Optimal pollution control models for interceptor sewers and overflow chambers. Proceedings of Computing and Control for the Water Industry '99, Exeter University, September 1999, 265-278.

22. Thomas N. S., Templeman A. B. and Burrows R. Optimal pollution control of large interceptor sewer systems. Proceedings of the 8th International Conference on Urban Storm Drainage, Sydney, August 1999, 1098-1106. 